\title{
On the effects of highway investment on the regional concentration of economic activity in the USA
}

\author{
Alfredo M. Pereira · Jorge M. Andraz
}

Received: 29 June 2011 / Accepted: 20 January 2012 / Published online: 4 February 2012 (C) Springer-Verlag 2012

\begin{abstract}
The empirical results in this note are based on state-level VAR estimates using private output, employment, and investment, as well as different measures of highway investment to capture, for each state, both the direct effects of highway investment in the state itself and spillover effects of highway investment in other states. Empirical results suggest that the largest states tend to also be the biggest beneficiaries of highway investments which means that highway investment has not only contributed to regional concentration of economic activity but has done so in many of the largest states thereby contributing to regional asymmetries in the country.
\end{abstract}

Keywords Public investment in highways - Concentration of economic activity

JEL classification $\mathrm{C} 32 \cdot \mathrm{H} 54 \cdot \mathrm{R} 53$

\footnotetext{
A. M. Pereira (B)

Department of Economics, College of William and Mary, Williamsburg, VA, USA

e-mail: ampere@wm.edu

J. M. Andraz

Faculdade de Economia, Universidade do Algarve, Faro, Portugal

e-mail: jandraz@ualg.pt

J. M. Andraz

CEFAGE (UE) - Center for Advanced Studies in Management and Economics,

Universidade de Évora, Évora, Portugal
} 